BIOINFORMATION

Discovery at the intereftace of physical and biologicat sceiences

\section{Design of New and Potent Diethyl Thiobarbiturates as Urease Inhibitors: A Computational Approach}

\author{
Abdul Wadood1*, Muhammad Riaz', Amir ul Mulk², Momin Khan², Sobia Ahsan Haleem³, \\ Sulaiman Shams', Sahib Gul', Ayaz Ahmed", Muhammad Qasim, Farman Ali ${ }^{6}$ \& Zaheer Ul- \\ Haq $^{7}$
}

1Computational Medicinal Chemistry Laboratory, Department of Biochemistry, Abdul Wali Khan University, Mardan, Pakistan; 2Department of Chemistry, Abdul Wali Khan University Mardan, Pakistan; ${ }^{3}$ National Center of Excellence in Molecular Biology, University Punjab Lahore, Pakistan; ${ }^{4}$ Department of Biotechnology, Abdul Wali Khan University Mardan, Pakistan; ${ }^{5}$ Department of Environmental Sciences, Abdul Wali Khan University Mardan, Pakistan; ${ }^{2}$ Department of Zoology, Abdul Wali Khan University Mardan, Pakistan; 7HEJ, Research Institute of Chemistry, University of Karachi, Karachi, Pakistan; Abdul Wadood - Email: awadood@awkum.edu.pk; Phone: +92 937 452195; Fax; +92 937 452195; *Corresponding author

Received March 27, 2014; Accepted April 03, 2014; Published May 20, 2014

\begin{abstract}
:
Urease is an important enzyme both in agriculture and medicine research. Strategies based on urease inhibition is critically considered as the first line treatment of infections caused by urease producing bacteria. Since, urease possess agro-chemical and medicinal importance, thus, it is necessary to search for the novel compounds capable of inhibiting this enzyme. Several computational methods were employed to design novel and potent urease inhibitors in this work. First docking simulations of known compounds consists of a set of arylidine barbiturates (termed as reference) were performed on the Bacillus pasteurii (BP) urease. Subsequently, two fold strategies were used to design new compounds against urease. Stage 1 comprised of the energy minimization of enzyme-ligand complexes of reference compounds and the accurate prediction of the molecular mechanics generalized born (MMGB) interaction energies. In the second stage, new urease inhibitors were then designed by the substitution of different groups consecutively in the aryl ring of the thiobarbiturates and N, N-diethyl thiobarbiturates of the reference ligands.. The enzyme-ligand complexes with lowest interaction energies or energies close to the calculated interaction energies of the reference molecules, were selected for the consequent chemical manipulation. This was followed by the substitution of different groups on the 2 and 5 positions of the aryl ring. As a result, several new and potent diethyl thiobarbiturates were predicted as urease inhibitors. This approach reflects a logical progression for early stage drug discovery that can be exploited to successfully identify potential drug candidates.
\end{abstract}

Key Words: Urease Inhibitor, Molecular docking, Interaction energy, H. pylori, MOE.

\section{Background:}

Urease (urea amidohydrolase; EC 3.5.1.5) a metalloenzyme catalyze the breakdown of urea into ammonia and carbon dioxide. Urease is present in a variety of plants, algae, fungi and bacteria [1-4]. Several microorganisms utilize urea as a source of nitrogen for growth. Urease plays an indispensable role in the nitrogen metabolism during the germination process of plant $[3,5]$. Unfortunately, the higher level of urease in soil is responsible for more rapid hydrolysis of urea, which leads to the phytophathic effects and loss of volatilized ammonia [6]. Moreover, urease is also a virulence factor in certain human being and animal ailments. Ureases play a crucial role in the 
progression of kidney stones, pyelonephritis, peptic ulcers leading to cancer, and other diseases [3]. The conspicuous remedy for treating infections caused by bacteria with antibacterials, yet, often proved to be unsuccessful [7]. Gastric cancer [8-9] is the fourth most frequent cancer and the second most frequent cause of cancer related deaths in the world [10].

At present, it is accepted that Helicobacter pylori (H. pylori) has an important contributing role in gastrointestinal tract infection [11]. Before neoplasia development, chronological changes in the gastric mucosa occur [12]. This comprises low level of inflammation and gastrointestinal membrane ulceration. Research has focused on the possibility that "oxidative stress" because of chronic inflammation might be a basic step in the series of pre-neoplastic events [13]. H. pylori infection leads to high expression of inducible nitric oxide synthase and nitric oxide production [14]. The species of reactive nitrogen oxides produces DNA damage and change in epithelial cell cycle [15]. Antioxidant enzymes like Catalase and superoxide dismutase might prevent the cell damage induced by the oxidative stress produced by $H$. pylori associated inflammation [14]. It has been observed in a clinical trial conducted in China that subjects taking antioxidant supplements have reduced rates of gastric related cancer death. Removal of the infection and/or dietary supplementation with $\beta$-carotene, vitamin $C$, or both agents separately, resulted in a considerable decrease in peptic lesions [16]. These findings support the assumption that oxidative stress might represent the final common path of $H$. pylori related carcinogenesis.

In the present study, interaction behaviors of nine arylidene barbiturates were predicted at the binding pocket of BP using molecular docking method. The synthesis and biological activities of arylidene barbiturates were recently reported by Khan, et al [17]. These compounds were docked in the binding site of the receptor and the energies of these complex structures were calculated via molecular mechanics generalized born (MMGB) method after post docking. New thiobarbiturates were then designed on the basis of obtaining findings and structural information.

\section{Methodology: \\ Receptor 3D structure preparation}

The three dimensional (3D) X-ray structure of BP urease with the resolution $1.55 \AA$ was retrieved from the protein data bank (http://www.rscb.org./pdb; code 4UBP) [18]. All the water molecules were removed from the structure and hydrogen atoms were added. This structure was then energy minimized with amber99 force field in the MOE Software packages (http://www.chempcomp.com). The three dimensional structure of the compounds were modeled using Builder software implemented on MOE. All the structures were then energy minimized using mmff 94 force field in MOE prior to molecular docking studies.

\section{Docking of compounds}

The docking of all the reference compounds into the binding pocket of BP urease were achieved using MOE-Dock implemented on MOE. Docking was carried out with London DG scoring function, triangle macher as placement method and 30 conformations for each compound were generated and stored in MOE database.

\section{Prediction of generalized Born interaction energies}

To identify potential compounds as urease inhibitors, the MMGB interaction energies of all the compounds and urease binding pocket were computed with generalized Born/volume integral (GB/VI) implicit solvent method [23] as implemented on MOE. The energy minimization was carried out using the conjugate gradient method by implementing the amber99 force field and distance-dependent dielectric potential with the rms gradient of 0.5 . During minimization, all heavy atoms in the protein were kept fixed. The MMGB interaction energy is the non-bonded interaction energy (van der Waals, Coulomb and GB implicit solvent interaction energies) between the receptor and the ligand whereas the ligand and receptor strain energies were not included in the calculations. Solvent molecules are ignored in the computation. Same protocol and units as mentioned in our previous article [24] was used in the present study for calculation of MMGB interaction energies. The MMGB/VI interaction energy serves as a descriptor in selecting the most active compounds.

\section{Selection of possible active BP urease inhibitors (Stage 1)}

The design of new compounds was based on the shared structure of the said compounds. These new compounds were designed by following, individual addition of substituent groups including $(-\mathrm{OH}),(-\mathrm{MtOH}),(-\mathrm{EtOH}),(-\mathrm{CHO}),(-\mathrm{NO} 2)$ and halogens onto the various positions of an aryl ring of thiobarbiturate as shown in Table 1 (see supplementary material). These new complexes were then energy minimized by the following steps: addition of the substituent groups to aryl ring followed by minimization with heavy atoms fixed.

The MM/GBVI interaction energies of these new protein-ligand complexes were then calculated. In stage 2, new compounds were designed based on information retrieved from the enzyme-ligand complexes that showed the lowest MM/GBVI interaction energies and close to the values produced by the reference molecules.

\section{Design of new BP urease inhibitors (Stage 2)}

It was noted that the complexes showing the lowest or closed interaction energies to the reference molecules were those substituted at ortho position of aryl ring of thiobarbiturates. So, in this stage, only these two positions of an aryl ring were substituted with various substituent groups. Subsequently, the MM/GBVI interaction energies and binding affinities were calculated and compared.

\section{Results \& Discussion:}

In the present study, calculations on the interactions at the binding pocket of Bacillus pasteurii urease (PDB entry Code 4 UBP) were carried out for nine arylidene barbiturates. All these compounds have shown to be potent inhibitors for the Bacillus pasteurii (BP) urease activity. Arylidene barbiturates are synthetic compounds synthesized by Khan, et al research group [17]. These compounds were docked into the receptor binding pocket and these complex structures were then energy minimized. Subsequently, MMGB interaction energy for each compound with the active site residues was calculated. New potent thiobarbiturate derivatives were then designed based on the structural requirement of the active site Bacillus pasteurii (BP) urease. 


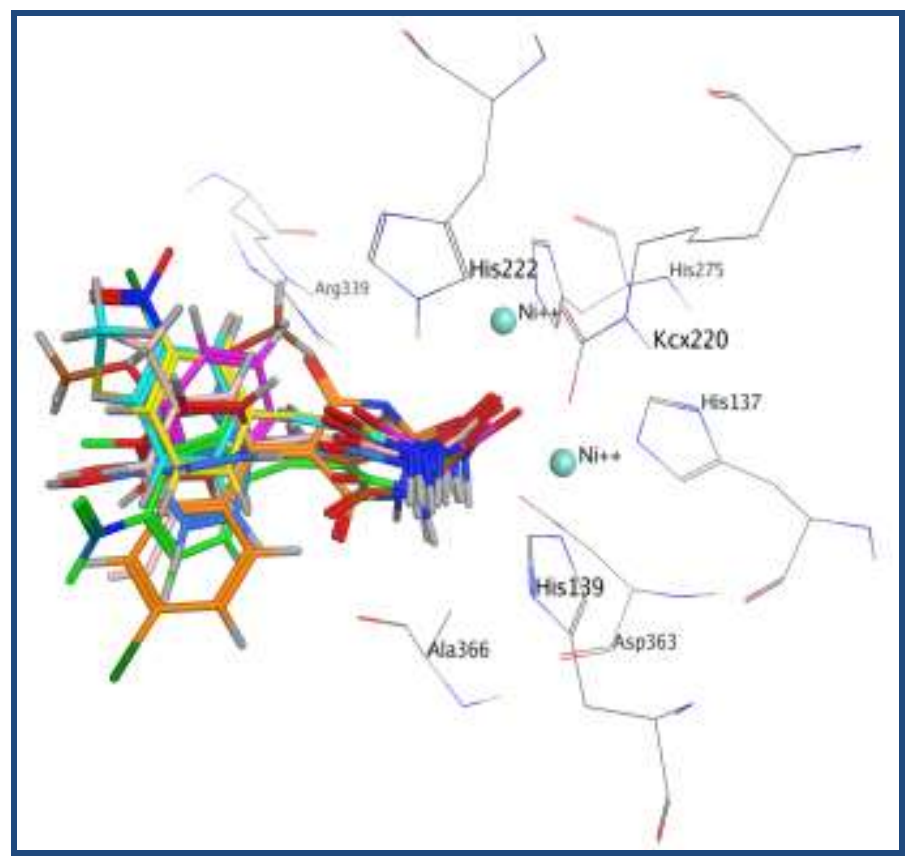

Figure 1: Superposition of arylidene barbiturates in the binding pocket of BP urease.

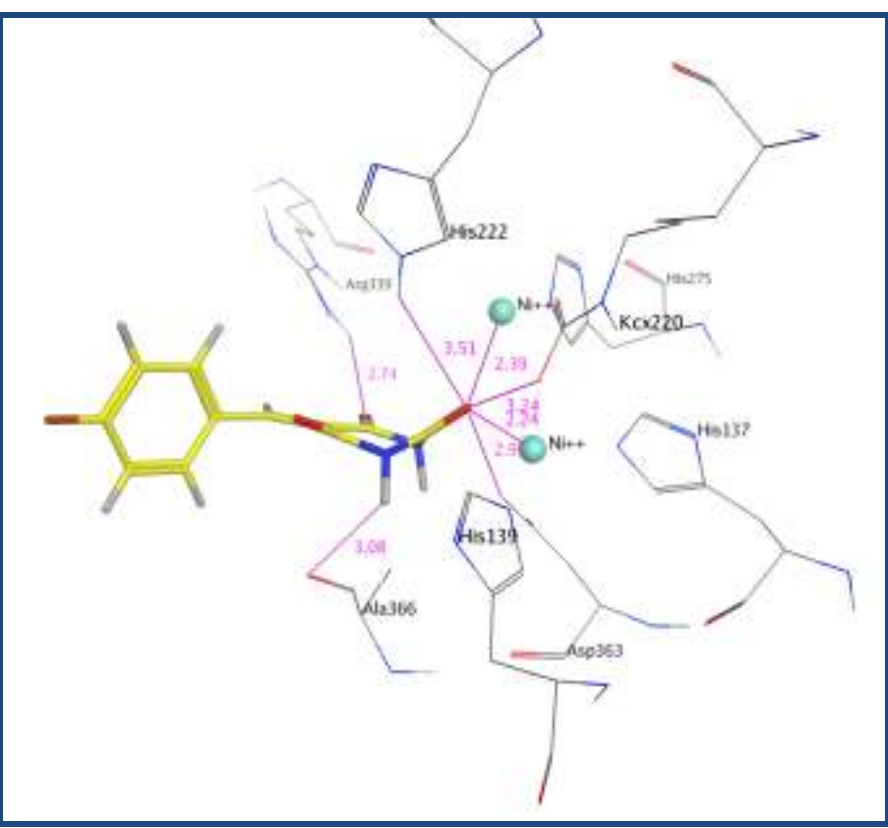

Figure 2: Spatial arrangement of binding pocket of BP urease for the most active reference compound.

\section{Docking of arylidene barbiturates to BP urease}

Nine arylidene barbiturates were docked into the binding pocket of BP urease. The superimposed view of the top ranked docked confirmations of these ligands (arylidene barbiturates) is shown in Figure 1. All the compounds were observed to adopt analogous conformations with a like binding mode around the binding site of $\mathrm{BP}$ urease and these compounds were observed to interact with nickel ions and the important binding pocket residues (His 137, His 275, Asp 363 etc.).

It has been shown in a number of reports that most of the urease inhibitors interact with nickel ions and the important active residues (His 137, His 275 etc.) [17-22]. The spatial arrangement of the most active compounds in the reference molecules (compound 1) bound to the binding pocket residues of urease is shown in Figure 2. One of the carbonyl oxygen of the compound 1 interact directly with both of the nickel atoms in the protein. Furthermore, the compounds also established hydrogen bonds with important active site residues (Figure 2). The MMGB interaction energy for all these compounds were computed and tabulated in Table 2 (see supplementary material). These results showed good correlation between the predicted interaction energies of these compounds and their biological activities. For example the most active compound (compound 1) was observed to have minimum MMGB interaction energy in the series. Whereas the compound having lowest activity was observed with highest MMGB interaction energy (Table 2).

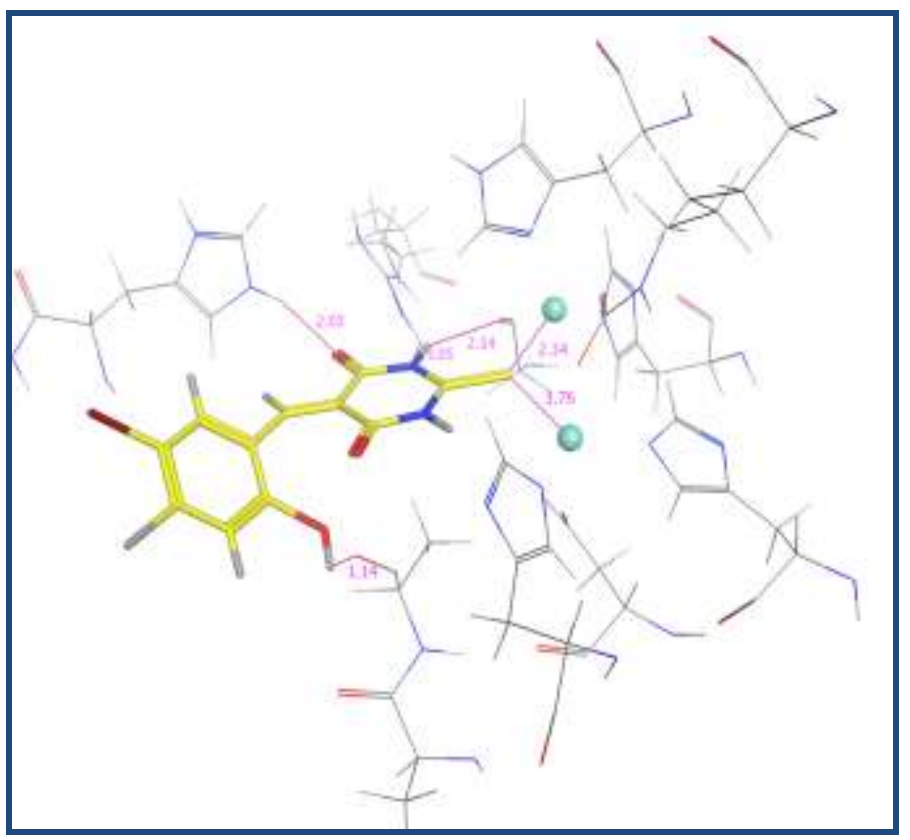

Figure 3: Spatial arrangement of the binding pocket of $\mathrm{BP}$ urease for the potent diethyl thiobarbiturate.

Design of new BP urease inhibitors based on arylidene barbiturates

New ligands with potential urease inhibitory activities were then designed, first replacing the oxygen of arylidene barbiturate with the sulfur atom and then adding various substituted aryl group in the R position, since this oxygen and the aryl ring gave the maximum contribution and has many possibilities for substitution. In the present study, several polar substituents including hydroxyl $(-\mathrm{OH})$, methoxy (-OMe), ethoxy (-OEt), nitro (-NO2), carbonyl (-CHO) and halogen group (i.e., $-\mathrm{Cl}$ ) were placed in different position of the aryl ring. These substituent groups were added individually on each position of the aryl ring.

This combination led us to design ninety five new thiobarbiturates that were docked into the active site of $\mathrm{BP}$ urease. The MMGB interaction energy was calculated for each compound. On the basis of MMGB interaction energy and visual inspection, fifteen compounds were predicted as the most active urease inhibitors. The MMGB interaction energies for these newly designed thiobarbiturates are summarized in Table 2. The derivative for the ligand having hydroxyl group at 
ortho position was observed to have lowest MMGB interaction energies as compare to compounds having hydroxyl group in other positions (Table 1).

Based on this finding, other positions in the aryl ring of diethyl thiobarbiturates were substituted with other groups and computed for MMGB interaction energies. The calculated binding interaction energies for these newly substituted derivatives were presented in Table 3 (see supplementary material). Generally, these compounds showed interactions within the binding pocket with residues as reported in a number of literatures [17-22]. The interaction of the most active diethyl thiobarbiturate derivative is shown in Figure 3.

Based on the hypothesis that the predicted MMGB interaction energies correlates with the biological activity, hence compounds with the lowest predicted MMGB interaction energies and closest to that of the reference molecules are supposed to be the most active. The MMGB interaction energies of these newly designed thiobarbiturates were calculated and the predicted interaction energies for the most active compounds $1 \mathrm{a}, 2 \mathrm{~b}, 8 \mathrm{~b}, 5 \mathrm{~b}, 18 \mathrm{~b}, 7 \mathrm{~b}$ and $13 \mathrm{~b}$ were $-22.95,-21.11$, $21.19,-20.18,-19.59,-19.22$ and $-19.12 \mathrm{Kcal} / \mathrm{Mol}$ respectively.

\section{Conclusions:}

The molecular docking of nine arylidene barbiturates as urease inhibitors were carried out on the active site of BP urease. In the present work, the MM/GBVI interaction energy was used as descriptor for selecting new candidates for BP urease inhibitors. The selection was performed in two stages. In the first stage substitutions were carried out individually for positions 1, 2, 3, 4 , and 5 of the aryl ring of thiobarbiturates. Based on the calculated MM/GBVI interaction energies, substitutions at ortho position of aryl ring of thiobarbiturates gave the lowest and closest interaction energies to the reference molecules. Consequently, the focus was placed on: ortho position for all the reference molecules. New compounds were designed by substituting various substituent groups on this position. The MM/GBVI interaction energies for all the new enzyme-ligand complexes were calculated. This approach reflects a logical progression for early stage drug discovery that can be exploited to successfully identify potent drug candidates.

\section{References:}

[1] Dixon NE et al. J Am Chem Soc. 1975 97: 4131 [PMID: 1159216]

[2] Sumner JB, J Saw Chem. 1926 69: 435

[3] Mobley HLT et al. Microbiol Rev. 1989 53: 85 [PMID: 2651866]

[4] Krajewska B et al. Wiad Chem. 2002 56: 223

[5] Zonia LE et al. Plant Physiol. 1995 107: 1097 [PMID: 7770520]

[6] Mulvaney RL et al. Soil Biochemistry, Marcel Dekker, Inc., New York, 1981, pp. 153. ISBN 0-8247-1131-9

[7] Bayerdorffer E et al. Scand J Gastroenterol. 1988 23: 93

[8] Devesa SS et al. Cancer. 1998 83: 2049 [PMID: 9827707]

[9] Howson CP et al. Epidemiol Rev. 1986 8: 1 [PMID: 3533579]

[10] Parkin DM et al. Eur J Cancer. 2003 39: 848.

[11] Lyon, France, International Agency for Research on Cancer, 1994, p. 177 ISBN 9283212614

[12] Correa P et al. Lancet. 1975 2: 58 [PMID: 49653]

[13] Correa P et al. Br Med Bull. 1998 54: 151 [PMID: 9604439]

[14] Pignatelli B et al. Eur J Cancer Prev. 1998 7: 439 [PMID: 9926291]

[15] Correa P et al. Tokyo, 1997, p. 22. ISBN: 978-4-431-65917-4

[16] Blot WJ et al. J Natl Cancer Inst. 1993 85: 1483 [PMID: 8360931]

[17] Khan KM et al. J Mol Graph Model. 2011 30: 153 [PMID: 21816644]

[18] Benini S et al. J Biol Inorg Chem. 2000 5: 110 [PMID: 10766443]

[19] Benini S et al. J Am Chem Soc. 2004 126: 3714 [PMID: 15038715]

[20] Benini S et al. Structure. 1999 15: 205 [PMID: 22890689]

[21] Musiani F et al. J Biol Inorg Chem. 2001 6: 300 [PMID: 11315566]

[22] Abid OR et al. J Med Chem Lett. 2010 1: 145.

[23] Labute P, J Comput Chem. 2008 29: 1693 [PMID: 18307169]

[24] Wadood A et al. J Mol Graph Model. 2013 40: 40 [PMID: 23353582]

Edited by $P$ Kangueane Citation: Wadood et al. Bioinformation 10(5): 299-307 (2014)

License statement: This is an open-access article, which permits unrestricted use, distribution, and reproduction in any medium, for non-commercial purposes, provided the original author and source are credited 


\section{Supplementary material:}

Table 1: The interaction energies of some diethyl thiobarbiturates as urease inhibitors

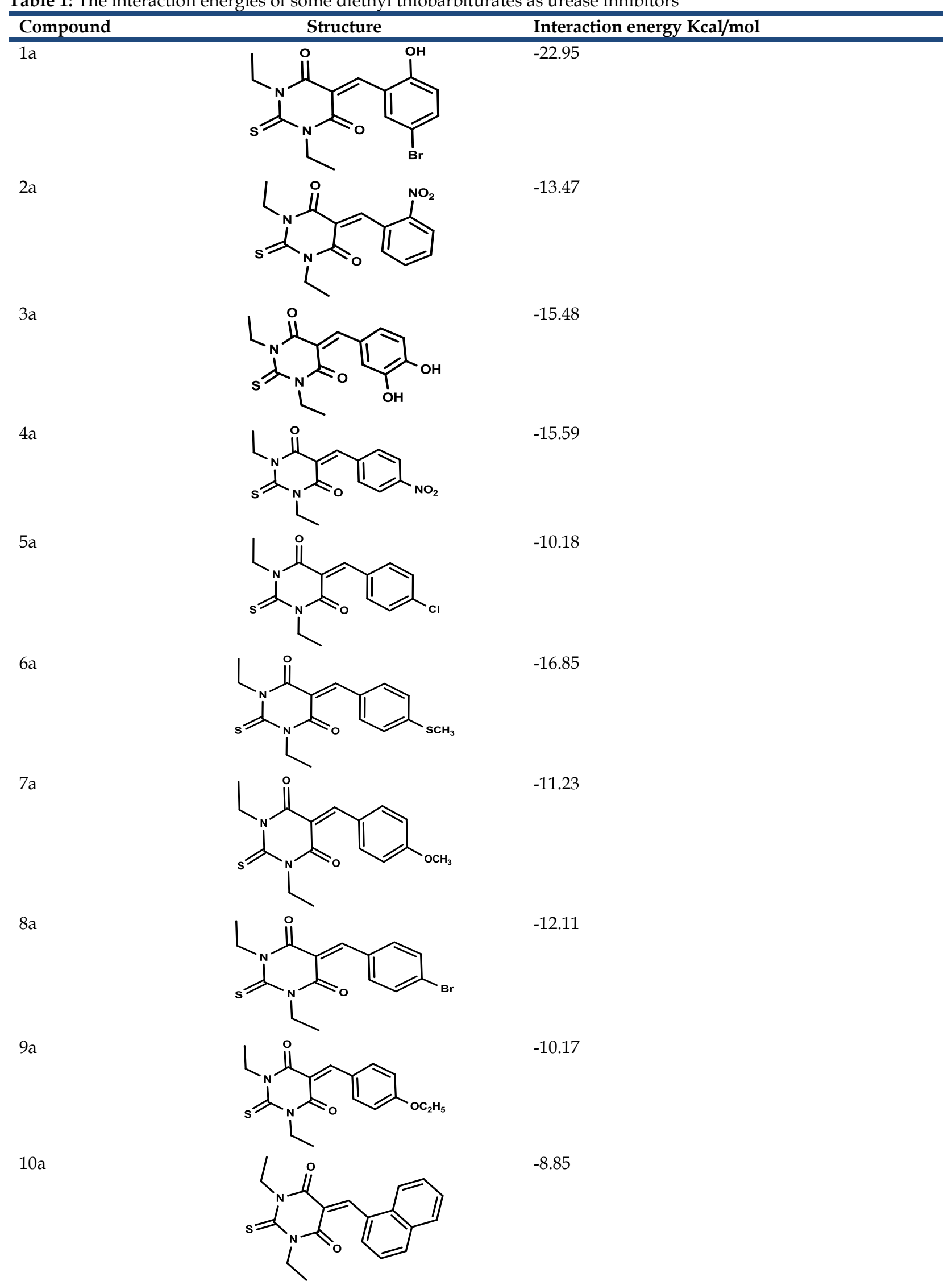


$11 \mathrm{a}$<smiles>CCN1C(=O)C(=Cc2cccc(Cl)c2)C(=O)N(CC)C1=S</smiles>

$12 \mathrm{a}$<smiles>CCN1C(=O)C(=Cc2cccc(Br)c2)C(=O)N(CC)C1=S</smiles>

$13 a$<smiles>CCN1C(=O)C(=Cc2cc(OC)c(OC)c(OC)c2)C(=O)N(CC)C1=S</smiles>

$14 a$<smiles>CCN1C(=O)C(=Cc2cccc(OC)c2OC)C(=O)N(CC)C1=S</smiles>

$15 a$<smiles>CCN1C(=O)C(=Cc2ccc([N+](=O)[O-])cc2)C(=O)N(CC)C1=S</smiles>

$-17.66$

$-13.28$

$-15.16$

Table 2: The interaction energies of arylidene barbiturates as urease inhibitors<smiles>CCNc1ccc(C=C2C(=O)NC(=O)NC2=O)cc1</smiles> 
6<smiles>O=c1nc2oc3ccccc3cc-2c(=O)[nH]1</smiles>

7<smiles>O=c1nc2oc3cc(Cl)ccc3cc-2c(=O)[nH]1</smiles>

8<smiles>O=c1nc2oc3ccc([N+](=O)[O-])cc3cc-2c(=O)[nH]1</smiles>

$41.6 \pm 1.2$

$23.6 \pm 1.3$

$66.7 \pm 0.3$

9<smiles>O=c1nc2oc3cccc(F)c3cc-2c(=O)[nH]1</smiles>

\section{Compound}

$1 \mathrm{~b}$<smiles>CCN1C(=O)C(=Cc2cc(Br)ccc2N)C(=O)N(CC)C1=S</smiles>

$3 b$<smiles>CCN1C(=O)C(=Cc2cc(Br)ccc2Cl)C(=O)N(CC)C1=S</smiles>

$4 \mathrm{~b}$<smiles>CCN1C(=O)C(=Cc2cc(Br)ccc2Br)C(=O)N(CC)C1=S</smiles>

$5 b$<smiles>CCN1C(=O)C(=Cc2cc(Cl)ccc2O)C(=O)N(CC)C1=S</smiles>

$6 b$<smiles>CCN1C(=O)C(=Cc2cc(Cl)ccc2Cl)C(=O)N(CC)C1=S</smiles>
Interaction energy Kcal/mol

$-21.11$

$-15.84$

$-20.18$ 
$7 \mathrm{~b}$<smiles>CCN1C(=O)C(=Cc2cc(Cl)ccc2F)C(=O)N(CC)C1=S</smiles>

$8 b$<smiles>CCN1C(=O)C(=Cc2cc(Cl)ccc2N)C(=O)N(CC)C1=S</smiles>

$9 b$<smiles>CCN1C(=O)C(=Cc2cc(N)ccc2Br)C(=O)N(CC)C1=S</smiles>

$10 \mathrm{~b}$<smiles>CCN1C(=O)C(=Cc2cc(N)ccc2O)C(=O)N(CC)C1=S</smiles>

$11 b$<smiles>CCN1C(=O)C(=Cc2cc(N)ccc2N)C(=O)N(CC)C1=S</smiles>

$12 b$<smiles>CCN1C(=O)C(=Cc2cc(N)ccc2Cl)C(=O)N(CC)C1=S</smiles>

$13 \mathrm{~b}$<smiles>CCN1C(=O)C(=Cc2cc(N)ccc2F)C(=O)N(CC)C1=S</smiles>

$14 \mathrm{~b}$<smiles>CCN1C(=O)C(=Cc2ccccc2F)C(=O)N(CC)C1=S</smiles>

$15 b$<smiles>CCN1C(=O)C(=Cc2ccccc2Cl)C(=O)N(CC)C1=S</smiles>

$16 \mathrm{~b}$<smiles>CCN1C(=O)C(=Cc2ccccc2O)C(=O)N(CC)C1=S</smiles>

$-19.22$

$-21.19$

$-16.15$

$-18.58$

$-17.96$

$-18.25$

$-19.12$

$-16.18$

$-17.83$

$-18.28$ 
$17 b$<smiles>CCN1C(=O)C(=Cc2ccccc2Br)C(=O)N(CC)C1=S</smiles>
$-15.73$

$18 \mathrm{~b}$<smiles>CCN1C(=O)C(=Cc2ccccc2N)C(=O)N(CC)C1=S</smiles>

$-19.59$ 